Article

\title{
Fatigue of Ti6A14V Structural Health Monitoring Systems Produced by Selective Laser Melting
}

\author{
Maria Strantza ${ }^{1, *}$, Reza Vafadari ${ }^{2,+}$, Dieter de Baere ${ }^{3,+}$, Bey Vrancken ${ }^{4,+}$, Wim van Paepegem ${ }^{2,+}$, \\ Isabelle Vandendael ${ }^{5, \dagger}$, Herman Terryn ${ }^{5, \dagger}$, Patrick Guillaume ${ }^{3, \dagger}$ and Danny van Hemelrijck ${ }^{1, \dagger}$ \\ 1 Department of Mechanics of Materials and Constructions, Vrije Universiteit Brussel, Brussels 1050, Belgium; \\ danny.van.hemelrijck@vub.ac.be \\ 2 Department of Materials Science and Engineering, Ghent University, Gent 9000, Belgium; \\ reza.vafadari@ugent.be (R.V.); wim.vanpaepegem@ugent.be (W.P.) \\ 3 Department of Mechanical Engineering, Vrije Universiteit Brussel, Brussels 1050, Belgium; \\ dieter.de.baere@vub.ac.be (D.B.); patrick.guillaume@vub.ac.be (P.G.) \\ 4 Department of Materials Engineering, KU Leuven, Leuven 3001, Belgium; bey.vrancken@mtm.kuleuven.be \\ 5 Department of Electrochemical and Surface Engineering, Vrije Universiteit Brussel, Brussels 1050, Belgium; \\ ivddael@vub.ac.be (I.V.); herman.terryn@vub.ac.be (H.T.) \\ * Correspondence: maria.strantza@vub.ac.be; Tel.: +32-262-929-25 \\ + These authors contributed equally to this work.
}

Academic Editor: Robert Lancaster

Received: 20 December 2015; Accepted: 25 January 2016; Published: 11 February 2016

\begin{abstract}
Selective laser melting (SLM) is an additive manufacturing (AM) process which is used for producing metallic components. Currently, the integrity of components produced by SLM is in need of improvement due to residual stresses and unknown fracture behavior. Titanium alloys produced by AM are capable candidates for applications in aerospace and industrial fields due to their fracture resistance, fatigue behavior and corrosion resistance. On the other hand, structural health monitoring (SHM) system technologies are promising and requested from the industry. SHM systems can monitor the integrity of a structure and during the last decades the research has primarily been influenced by bionic engineering. In that aspect a new philosophy for SHM has been developed: the so-called effective structural health monitoring (eSHM) system. The current system uses the design freedom provided by AM. The working principle of the system is based on crack detection by means of a network of capillaries that are integrated in a structure. The main objective of this research is to evaluate the functionality of Ti6Al4V produced by the SLM process in the novel SHM system and to confirm that the eSHM system can successfully detect cracks in SLM components. In this study four-point bending fatigue tests on Ti6Al4V SLM specimens with an integrated SHM system were conducted. Fractographic analysis was performed after the final failure, while finite element simulations were used in order to determine the stress distribution in the capillary region and on the component. It was proven that the SHM system does not influence the crack initiation behavior during fatigue. The results highlight the effectiveness of the eSHM on SLM components, which can potentially be used by industrial and aerospace applications.
\end{abstract}

Keywords: selective laser melting; titanium alloy; structural health monitoring; fatigue; fractography

\section{Introduction}

A wide range of different additive manufacturing (AM) technologies exists, and they vary in the way layers are built, how the base material is applied and the materials that can be used [1]. Some methods use melting to create the layers, whereas others methods deposit liquid materials that can then be cured and hardened [2]. For the production of metallic parts, there are three main processes, 
namely selective laser melting (SLM), laser metal deposition and electron beam melting. SLM was developed from the selective laser sintering process [3,4]. In SLM, energy provided by a laser beam is used layer-wise to fully melt powder particles to each other [3]. One of the main advantages of SLM is the high level of flexibility to create complex geometrical structures that are not easy or even possible to be produced by conventional production methods. Other advantages are a lower time-to-market, a near-net-shape production without the necessity of molds, a high material utilization rate and direct production based on a computer aided design (CAD) model [5].

However, all the AM processes, including SLM, have intrinsic limitations. Internal stresses and the risk of porosity [6-9] are critical parameters that can provoke a detrimental impact on the fatigue life of the components [10]. During the manufacturing process, high thermal gradients cannot be avoided and after the cooling down residual stresses are locked in the component. On the other hand, defects are formed during the process between the layers [5]. Large, irregular pores are created in between layers and scan tracks due to incomplete or bad melting conditions, while small, spherical pores become encapsulated due to the presence of gas in the solidifying melt pool. Both residual stresses and defects may have a detrimental effect in the fatigue life [11]. Fatigue, as one of the principal fracture modes, occurs due to damage caused from cyclic stresses and can affect the structural integrity of a metallic structural component [5,12]. Cyclic slip in slip bands is considered to be critical for microcrack nucleation, and it is related with cyclic dislocation movements [13]. Microcracks typically nucleate and initiate at the outer surface of the component since the restrain on a cyclic slip is lower at the outer surface than in the inner part of a component [14]. Nevertheless, porosities or other defects can act as stress concentrators and nucleate a crack internally. Fracture in engineering alloys can occur by transgranular (through the grains) or intergranular (along the grain boundaries) fracture paths. It is known that fatigue life is characterized by crack initiation, crack propagation and final failure [13]. A fracture analysis of the surface of the component is essential to understand the cause of the failure. The fracture surface as a detailed record of a part's failure history can give important information with respect to the loading history, material quality, environmental effects and crack path [12,14,15].

On the other hand, structural health monitoring (SHM) is used to provide fast and reliable information about the integrity of the structure at any time if required. In engineering structures, implementing damage detection is compulsory to improve life-safety and to reduce the direct operational costs [16]. During the past years, the developments of SHM systems were inspired by bionic engineering [17-19]. Specifically, the structures are equipped with embedded sensor systems which are able to detect cracks in a similar way as a biological nervous system. Still, installing an effective, durable and robust SHM system in real operational conditions remains challenging.

In this study, a novel SHM system, which is called an effective structural health monitoring (eSHM) system, is used. The current system integrates a network of capillaries into a structure. The primary philosophy of the system is based on recording the absolute fluid pressure changes in the network of capillaries or cavities. A pressure change in the capillary identifies the presence of a crack. A detailed and extended review of the eSHM system can be found in the literature [20]. The practical implementation of the new eSHM system is challenging from a production point of view. In reality it is not easy to integrate a complex network of capillaries in a metallic structure by means of subtractive manufacturing technologies. AM technologies like SLM are promising technologies that show a potential to implement eSHM systems for fatigue crack detection in complex structures. Previous research based on the eSHM system was conducted on SS 316L specimens in order to evaluate the working principle of the system and the feasibility of using laser metal deposition for the production [20]. The main objective of this study is to evaluate the effectiveness of the eSHM system on detecting cracks in SLM components and to evaluate the functionality of the Ti6Al4V in the eSHM systems. In this paper, Ti6Al4V parts with integrated capillaries of $1 \mathrm{~mm}$ diameter are manufactured. The fatigue behavior is investigated by means of a four-point bending test, with special attention to the crack detection. During the fatigue tests, the specimens were tested according to the step method with a constant fatigue stress amplitude and a constant stress ratio ( $R$ ratio) in each step. The crack initiation 
sites are investigated through micrograph observation of the fracture surfaces via scanning electron microscopy (SEM). Finite element method (FEM) simulations are also used in order to correlate the high stress concentration positions with the crack initiation sites.

\section{Experimental Study}

\subsection{Materials and Production}

The material used for this study is Grade 23 Ti6Al4V-ELI. Seven specimens were produced by SLM (Leuven, Belgium). Six of them remained in as-built (AB) conditions and one in stress relieved (SR) conditions. The first four specimens and the stress relieved specimen were produced by Layerwise NV. Specimens 5 and 6 were produced on an in-house developed LM-Q machine of the PMA Division (Production Engineering, Machine Design and Automation) of KU Leuven. The LM-Q machine is equipped with a fibre laser -IPG YLR-300 SM Yb:YAG. The current laser provides with a beam of $1070 \mathrm{~nm}$ (maximum power of $300 \mathrm{~W}$ ) and a Gaussian intensity distribution. For the production of the current specimens the spot diameter was selected to be $80 \mu \mathrm{m}$. The scanning velocity varied from 3 to $2000 \mathrm{~mm} / \mathrm{s}$, the spatial resolution of the beam movement was about $1 \mu \mathrm{m}$ and the platform was lowering in steps of $1 \mu \mathrm{m}$. In order to avoid oxidation during manufacturing, the production chamber was evacuated and filled with inert argon atmosphere. Specimens were built up by first scanning the contours of the layer. The scanning direction of successive layers was rotated by an angle of $90^{\circ}$. In one layer, a bidirectional scanning pattern was applied. A layer of $30 \mu \mathrm{m}$ was chosen and the specimens were built in vertical direction. The powder spherical particles were made by plasma atomization process. For most of the powder volume the particle size varies between 5 and $50 \mu \mathrm{m}$ while some particles are smaller than $34.4 \mu \mathrm{m}$.

The integrated capillary for the SLM Ti6Al4V specimens had a diameter of $1 \mathrm{~mm}$ and a sinusoidal shape with an amplitude of $2 \mathrm{~mm}$. The period of the sinusoidal shape was $20 \mathrm{~mm}$ for the first four samples and the stress relieved specimen and $22.4 \mathrm{~mm}$ for the last two samples. After the SLM production the specimens were milled to final dimensions as specified in Figure 1. The capillary is not placed symmetrically in the middle of the specimens but close to the surface ( $4 \mathrm{~mm}$ away from the surface) on the tension side during the four-point bending test. The building direction (BD) is also indicated in Figure 1. The static tensile properties for the SLM Ti6Al4V were previously published in the literature [21] and are presented in Table 1. For the six SLM specimens that remained in as-built conditions, no stress relief or any heat treatment conditions were applied prior testing, while for one specimen a heat treatment of $2 \mathrm{~h}$ for $530^{\circ}$ was applied in order to obtain SR conditions without altering the microstructure.

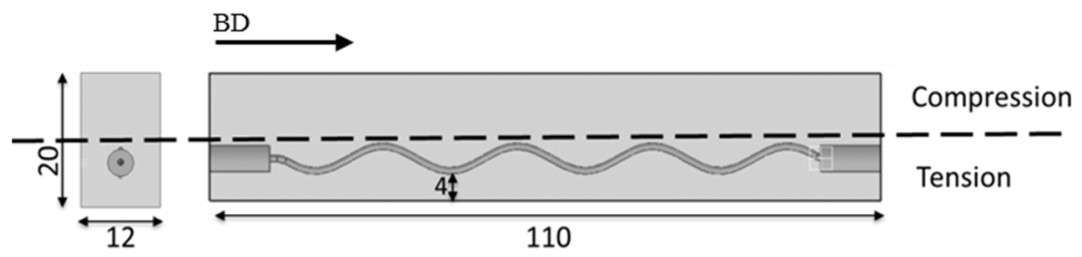

Figure 1. Four-point bending specimen's dimensions (mm): 2D side and front views.

Table 1. SLM Ti6Al4V mechanical properties from [21].

\begin{tabular}{cccc}
\hline$\sigma_{\text {yield }}[\mathrm{MPa}]$ & $\sigma_{\text {UTS }}[\mathrm{MPa}]$ & $\varepsilon[\%]$ & $E_{\text {tension }}[\mathrm{GPa}]$ \\
\hline $1125 \pm 22$ & $1216 \pm 8$ & $6 \pm 0.4$ & 114 \\
\hline
\end{tabular}

In order to compare the obtained results from SLM specimens with conventional Ti6Al4V material, three specimens were prepared from plate and mill annealed Ti6Al4V. These samples had the same geometry as the SLM samples and no capillary was present. 


\subsection{Test Procedure}

The specimens were subjected to a cyclic fatigue loading in a four-point bending setup. A schematic representation of the four-point bending fatigue test is depicted in Figure 2. The locations with the highest probability for crack initiation from the capillary are situated at the capillary borders that are furthest away from the neutral axis in the tension area of a four-point bending test specimen (see Figure 1). The principal reason for this higher probability is directly related to the higher stress concentration at these locations. According to the step-method the initial stress amplitude is chosen below the fatigue limit of a specimen. For each step a large number of cycles $N(500,000)$ with the same loading are applied. If failure does not occur, the stress amplitude is increased with a selected step and again a block of $\mathrm{N}$ cycles is applied [22,23]. This procedure is repeated until failure occurs. This approach is known as step-method, and it is suggested in the literature as a fast methodology for the generation of Haigh diagrams and determines the fatigue limit of a specimen. In the current study the attention is focused on the fatigue life of the specimen on the last step and on the stress level of the crack detection by means of the eSHM system. There are a few studies in the literature that demonstrate results on Ti6Al4V specimens produced by the SLM process [24-26]. However, since no previous results were available for the endurance limit of the additive manufactured Ti6Al4V of similar specimens with capillaries, a sufficiently low stress starting points was chosen.

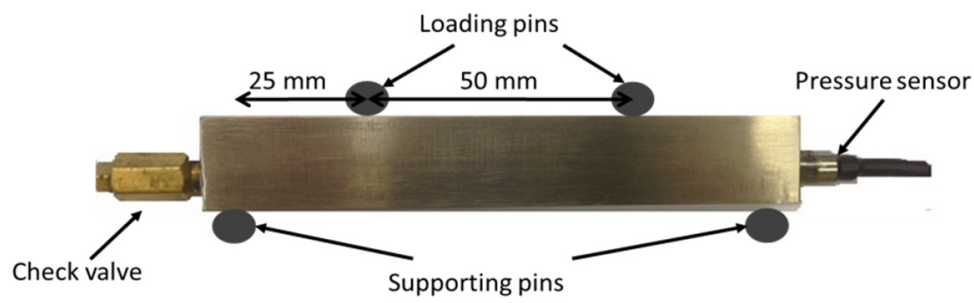

Figure 2. Schematic of four-point bending setup with the specimen and the installed pressure sensor.

The fatigue tests were carried out on an MTS machine with a maximum static and dynamic load capability of $100 \mathrm{kN}$. The applied sinusoidal cyclic load in each step had constant amplitude with an $R$ ratio equal to 0.1 and frequency of $15 \mathrm{~Hz}$. During the tests the pressure transducer, the actuator load and displacement were monitored and registered by the controller of the MTS machine.

A pressure transducer (Kulite XTL-123C-190M-1, 7-BAR-A, Leonia, USA) was placed at one side and a check valve (Clippard MCV-1-M5, Cincinnati, USA) at the other side of the specimen, as shown in Figure 2. After sealing, each specimen was placed in a vacuum chamber at a pressure of 0.5 bar. As a last stage an extra stop (Clippard 11755-M5-PKG, Cincinnati, USA) was installed on the check valve. The final test specimen is shown in Figure 2. After the crack detection, the test was stopped and the specimens were inspected by liquid penetrant inspection (LPI) in order to locate the crack. After this inspection, samples were again subjected to the fatigue test until failure occurred. To analyze the influence of the eSHM system on the microcrack initiation, the fracture surfaces obtained after the fatigue tests were analyzed with the optical microscope and the SEM. For the microstructural examination, the specimens were embedded in epoxy resin, ground using 1200 grit $\mathrm{SiC}$ paper and polished using a $0.25 \mu \mathrm{m} \mathrm{SiO} 2 / \mathrm{H}_{2} \mathrm{O} / \mathrm{H}_{2} \mathrm{O}_{2}$ suspension. After the preparation the specimens were etched for $10 \mathrm{~s}$ in a solution of $50 \mathrm{~mL} \mathrm{H}_{2} \mathrm{O}, 25 \mathrm{~mL} \mathrm{HNO}_{3}$ and $5 \mathrm{~mL}$ HF. A Leica Metallovert microscope was used in order to examine the microstructure.

Furthermore, a finite element approach was chosen as the simulation method to interpret the observations throughout the fatigue experiments. The model was built in ABAQUS commercial software version 6.13.1 [27]. Dimensions and displacements are in $\mathrm{mm}$, stresses in $\mathrm{MPa}$ and forces in $\mathrm{kN}$. The mechanical properties of the SLM Ti6Al4V that are exploited in the numerical model are given in Table 1, with a Poisson ratio of 0.32 . 


\section{Results and Discussion}

\subsection{Fatigue Results}

The specimens were subjected to fatigue testing. Table 2 shows an overview of all the analyzed specimens with the stress levels at which a crack was detected by means of the eSHM. Initially, Specimen 1 was subjected to a low stress level. For each stress level a constant block of 500,000 cycles was defined as run-out. As previously mentioned, if failure did not occur in the period of the first block, the stress was increased. This procedure continued until a crack was detected in Specimen 1 by the eSHM system in the 12th step after 14,506 cycles. For Specimen 2, a stress level lower than the stress level of crack detection in Specimen 1 was chosen. This stress level corresponded to the stress level of the 10th step of Specimen 1 (488 MPa). Although Specimen 1 successfully withstood 500,000 cycles under a stress level of $488 \mathrm{MPa}$, in Specimen 2 a crack was already detected after 146,988 cycles. Due to this unexpected early failure the initial stress level for Specimen 3 was set to $323 \mathrm{MPa}$. Unfortunately, the eSHM system of Specimen 3 detected cracking after 493,782 cycles at the starting stress level of $323 \mathrm{MPa}$. This stress level can be considered relatively low, since it is only $29 \%$ of the $\sigma_{\text {yield }}$ of the SLM specimens. The fatigue life and the low stress levels that were achieved by both Specimens 2 and 3 moved the initial stress level of Specimen 4 to an even lower value (158 MPa). Specimen 4 was detected to be cracked at the stress level of $571 \mathrm{MPa}$. The fatigue test of Specimen 5 started at a stress level of $207 \mathrm{MPa}$, and cracking was detected at a stress level of $537 \mathrm{MPa}$ after 11 steps. For the last specimen the initial stress level was set to $455 \mathrm{MPa}$ and the crack was detected at $620 \mathrm{MPa}$. On the other hand, for the SR specimen, the initial stress level was selected based on the behavior of the Specimen 4 (due to similarities of the capillary geometry). The initial stress level was $405 \mathrm{MPa}$, and the crack was detected at the stress level of $818 \mathrm{MPa}$. It is clear that the stress relief has significantly improved the fatigue response of the SLM component.

Table 2. Overview of the different steps and stress levels for the SLM Ti6Al4V specimens and conventional Ti6Al4V specimens.

\begin{tabular}{cccc}
\hline SLM Specimens & Total Steps & Stress Level at Crack Detection & Cycles at Crack Detection \\
\hline Specimen 1 & 12 & $591 \mathrm{MPa}$ & 14,506 \\
Specimen 2 & 1 & $488 \mathrm{MPa}$ & 146,988 \\
Specimen 3 & 1 & $323 \mathrm{MPa}$ & 493,782 \\
Specimen 4 & 6 & $571 \mathrm{MPa}$ & 252,838 \\
Specimen 5 & 11 & $537 \mathrm{MPa}$ & 82,494 \\
Specimen 6 & 3 & $620 \mathrm{MPa}$ & 167,478 \\
SLM (SR) & 6 & $818 \mathrm{MPa}$ & 113,104 \\
\hline Conventional & Total Steps & Stress Level at Failure & Cycles at Failure \\
\hline Specimen 1 & 15 & $820 \mathrm{MPa}$ & 40,399 \\
Specimen 2 & 8 & $819 \mathrm{MPa}$ & 300,390 \\
Specimen 3 & 3 & $819 \mathrm{MPa}$ & 186,599 \\
\hline
\end{tabular}

In total five, SLM specimens were subjected to fatigue at stress levels above $530 \mathrm{MPa}$. While on Specimens 2 and 3, the crack was detected at stress levels below $530 \mathrm{MPa}$. In Specimen 2 the initial stress level was $488 \mathrm{MPa}$ while in Specimen 3 the initial level was $323 \mathrm{MPa}$. In both samples the crack was detected by the system in the first stress level of the fatigue test. Table 2 shows also the data of conventional plate Ti6Al4V samples as a reference for defect free samples. It can be noted that all the specimens failed at approximately the same stress level of $820 \mathrm{MPa}$.

Figure 3 indicates the maximum tensile stresses obtained by conventional and SLM titanium specimens. Severe scatter is noted for the fatigue stress levels of components produced by SLM in as-built conditions (between 488 and $620 \mathrm{MPa}$ ). In contrast, conventional specimens show higher repeatability since the probability of internal defects is negligible compared to additively manufactured 
specimens. The stress level of Specimen 3 is significantly lower than the average value of the other five SLM samples. The obtained value of the conventional Ti6Al4V specimens is $32.3 \%$ higher than the highest value obtained for SLM parts in Specimen 6. On the other hand, the maximum tensile stress obtained by the SR SLM specimen reached similar stress level ( $818 \mathrm{MPa})$ as the conventional Ti6Al4V specimen. This is an indication that residual stresses significantly affect the fatigue behavior of SLM produced parts, as suggested in the literature [28]. Overall, in additively manufactured components and especially on specimens with vertical building direction, vertical stresses are dominant over the horizontal stresses. Compressive residual stresses in the middle of the specimen are balanced by high tensile stresses that are present at the edges of the specimens $[7,29,30]$. As a consequence, the expected tensile stresses of the specimens' sides could be released by a stress relief heat treatment and improve the fatigue response. Due to the lack of more stress relieved specimens, this influence is not discussed in detail in this article. The scatter on the maximum stress levels and the fatigue life may be attributed to local porosity, residual stresses and microstructure of the SLM specimens. It is known that imperfections due to the SLM process may have a big effect on the mechanical properties of samples [28].

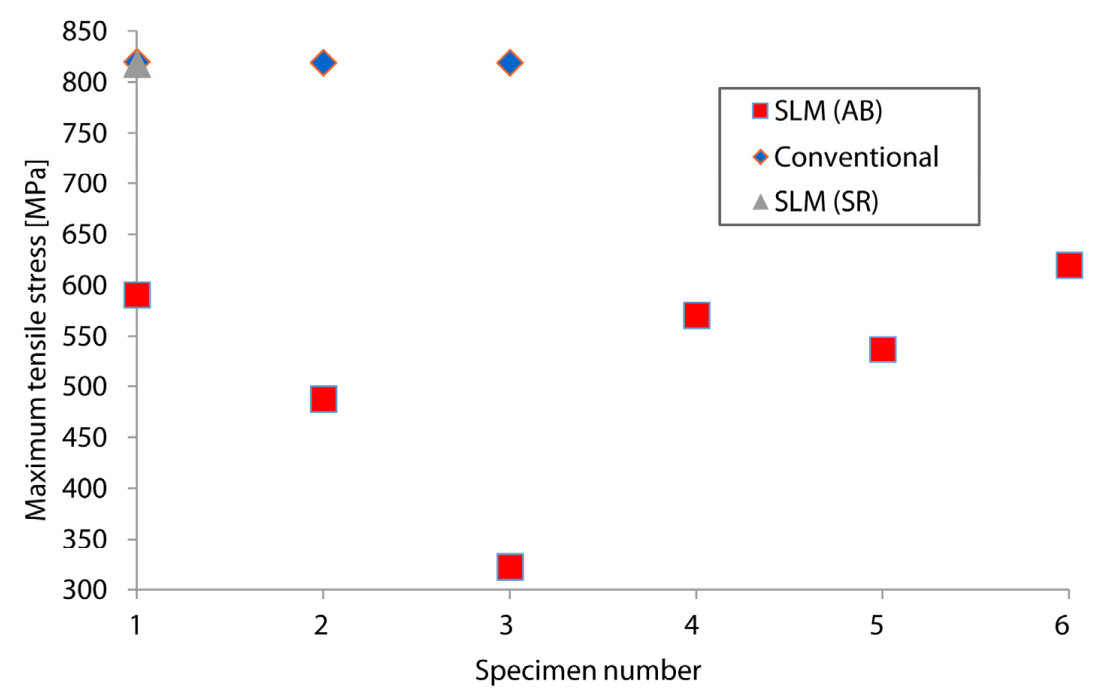

Figure 3. Maximum stress vs. specimen numbers for the conventional and SLM Ti6Al4V specimens in as-built (AB) and stress relieved (SR) conditions.

\subsection{Crack Detection during Fatigue Testing}

During fatigue experiments the pressure in the capillary was continuously monitored by the pressure sensor. For both specimens the pre-set limit was set to 0.8 bar at the beginning of the test. When a crack penetrates the capillary, the pre-set limit of the pressure sensor is reached, and the fatigue test stops. Figure 4 shows the pressure as a function of the time for the last second of the fatigue test for Specimens 3 and 5. A periodic variation in the pressure due to the cyclic deformation of the specimens is clearly observed for the last load cycles applied to Specimens 3 and 5 (see Figure 4a,b).

When a crack opens, the pressure inside the capillary will increase and finally reach atmospheric pressure. Since the loading is cyclic, and the crack is open only a fraction of each cycle, the pressure will thus approach atmospheric pressure in steps. Examining these graphs, one can observe that there is a difference in the pressure behavior between Figure 4a,b. In Specimen 3 (Figure 4a), the pressure increased gradually until the threshold is reached. As it is depicted from Figure $4 \mathrm{a}$, the increasing behavior possibly took place already from the previous applied cycles, which are not graphically presented in the current graph. In Figure $4 \mathrm{~b}$ the pressure is stable until $0.64 \mathrm{~s}$, where there is a sudden increase, and, a tenth of a second later, the pressure has already reached ambient pressure. Specimen 
4 showed behavior similar to Figure 4a, while Specimens 1, 2, 6 and the SR specimen exhibited a pressure-time evolution comparable to Figure $4 \mathrm{~b}$.

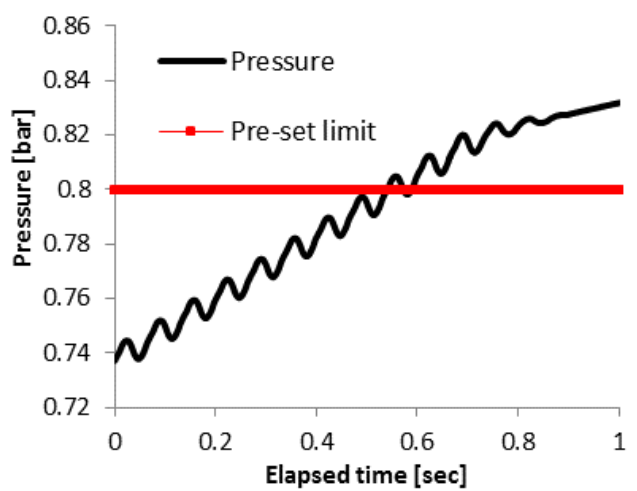

(a)

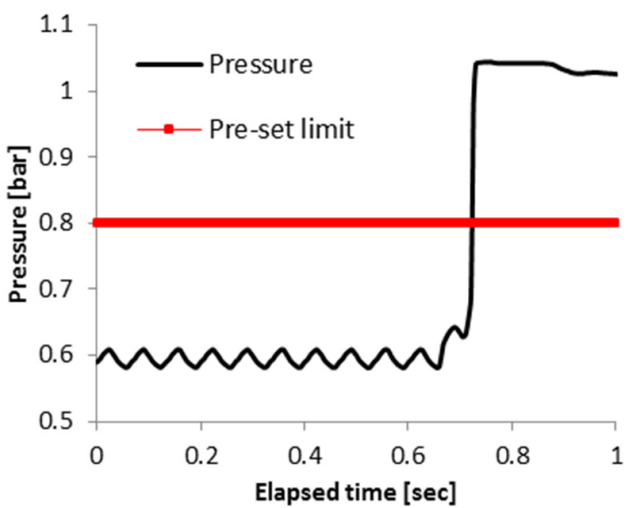

(b)

Figure 4. Pressure vs. elapsed time for (a) Specimen 3; and (b) Specimen 5 produced by SLM during the last second of the fatigue test.

It is important to mention that in Specimen 5 the maximum pressure is the ambient pressure which is approximately 1 bar, while in Specimen 3 the maximum pressure is only 0.83 bar. For both specimens the last $0.2 \mathrm{~s}$ of the test was in stress-free conditions since the pre-set limit activated the stopping procedure of the fatigue test. In the case of Specimen 5 the crack opening was large enough to reach atmospheric pressure in the capillary. In Specimen 3, although it looks like the pressure is still rising, after the last second, the crack was sealed, since a pressure of 0.83 bar could be maintained within the capillary. Evidence of crack closure was further provided by the LPI that was conducted in order to locate the crack [23]. In the case of Specimen 3 the liquid penetrant did not give a correct crack indication due to the fact that the crack was sufficiently closed to prevent the penetration of the liquid. In Specimen 5 the crack opening was probably wider than in Specimen 3. In addition to that, the stress level of Specimen 5 is higher $(537 \mathrm{MPa}$ ) that the stress level of Specimen 3 (323 MPa). It is important to note that, although the increase in capillary pressure in Specimen 5 was sudden, the specimen did not fail completely, indicating that the structural health monitoring system discussed in this paper can also be used in the case of fast crack propagation.

\subsection{Fracture Surface Analysis}

In order to study the presence of porosity and the influence of the capillary on the crack initiation and the fatigue life, the obtained fracture surfaces were examined. Figures 5-7 show micrographs of the crack initiation sites and the capillary regions for selected specimens produced by SLM. As previously mentioned, Specimen 6 was the specimen with the highest stress level at the crack detection. Figure 5 shows the micrograph of the fracture surface of Specimen 6. It can be seen that the crack nucleated due to a subsurface defect situated in the tension area of the specimen (Figure 5a). The red squares shown in Figure 5a are the regions shown at higher magnification in the next pictures of Figure 5. The capillary region is visible in Figure $5 b$, and no crack initiation signs can be seen. In Figure $5 c, d$, it is observed that the defect is very small lack-of-fusion region, showing rounded blister-like patterns on the surface, which indicates that it is not part of the fracture surface. The area around the nucleation site displayed brittle fracture (Figure 5e), while the fast fracture surface (see Figure 5f) exhibits a ductile fracture behavior, which is common for as-built specimens [9]. In the case of Specimen 6, although the stress level was high compared to the other specimens, the fatigue life was fairly low in the last stress level. 


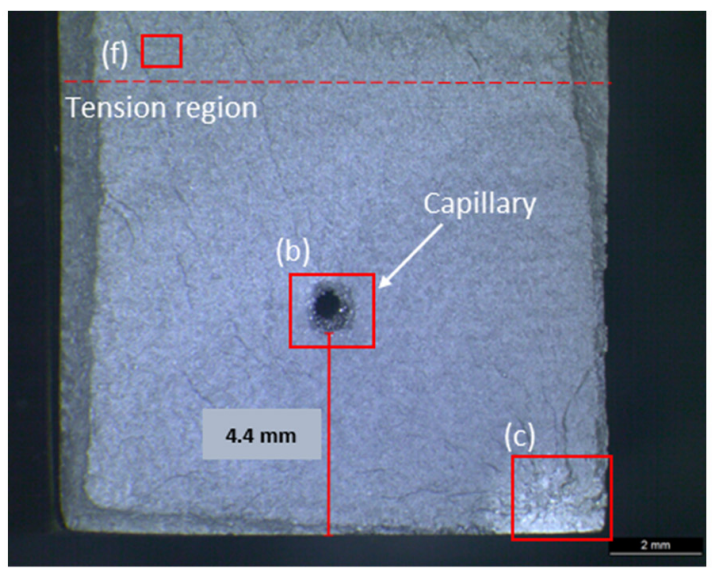

(a)

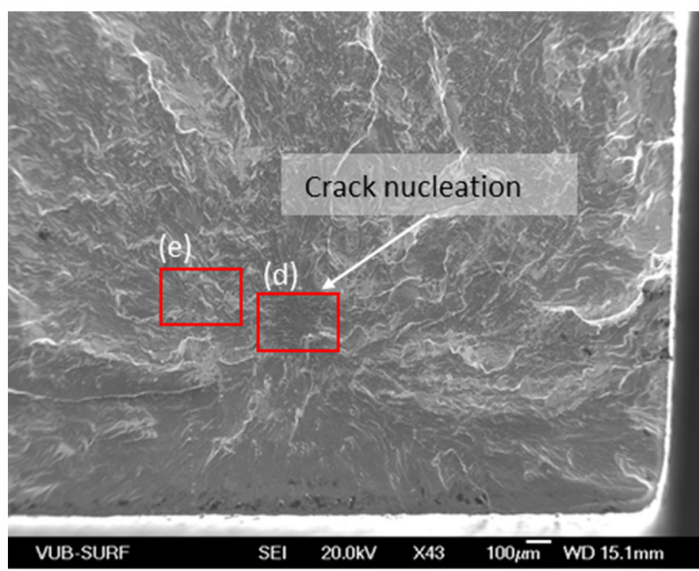

(c)

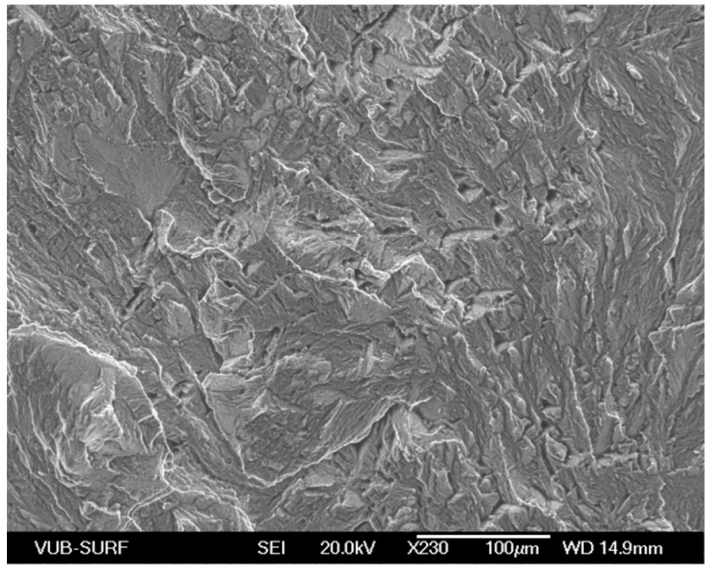

(e)

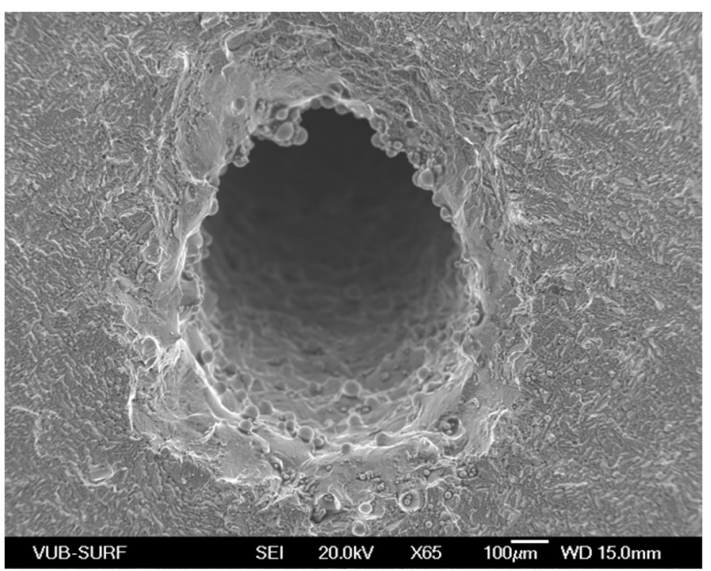

(b)

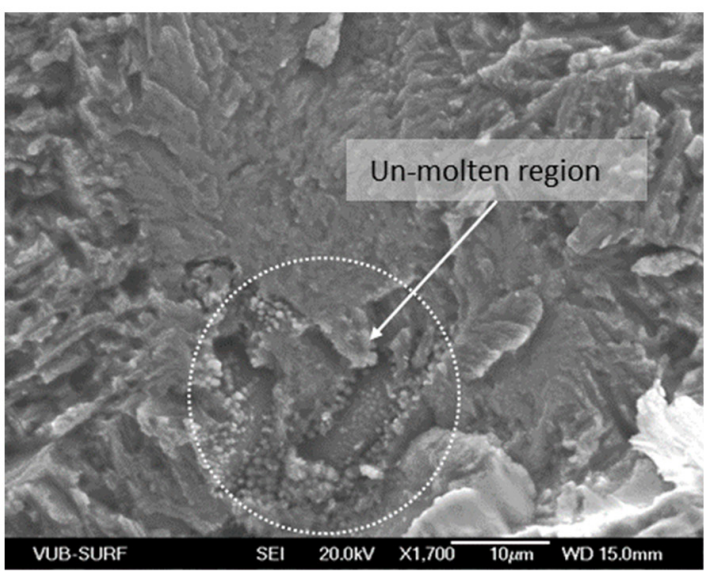

(d)

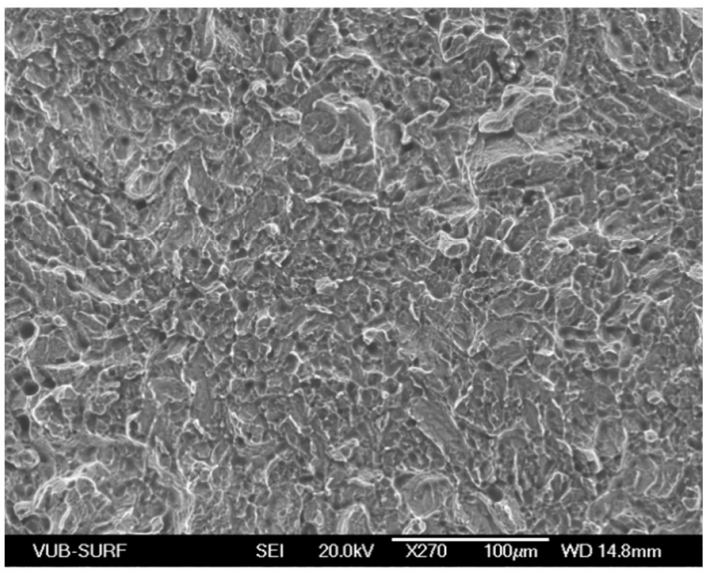

(f)

Figure 5. SEM micrographs of a fracture surface of Specimen 6 with maximum stress of $620 \mathrm{MPa}$. The fracture surface is shown in (a) and the capillary region is shown in (b) in high magnification; $(\mathbf{c}, \mathbf{d}, \mathbf{e})$ depict the corresponding crack initiation point, while (f) shows the fast fracture region.

Figure 6 indicates that the crack initiated at two places in Specimen 5, namely at the capillary region and close to the corner of the specimen. The defects concentrated at the bottom of the specimen consist of pore inclusions with a diameter of approximately $10 \mu \mathrm{m}$ and lack-of-fusion regions, see Figure $6 \mathrm{~b}$. On the other hand, another crack initiation site was detected on the right side of the capillary (see dashed region in Figure 6c). Furthermore, un-molten regions with powder and 
splatter particles were also located around the capillary, which can increase detrimentally the stress concentration in that region (see dashed region in Figure 6d).

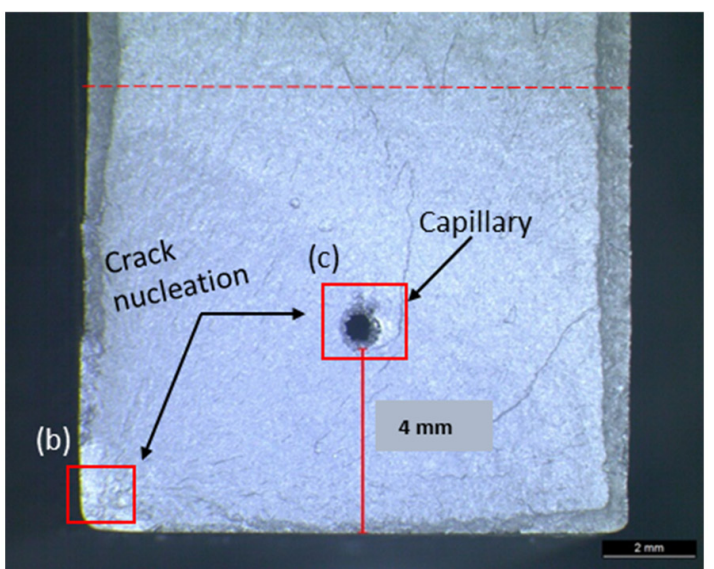

(a)

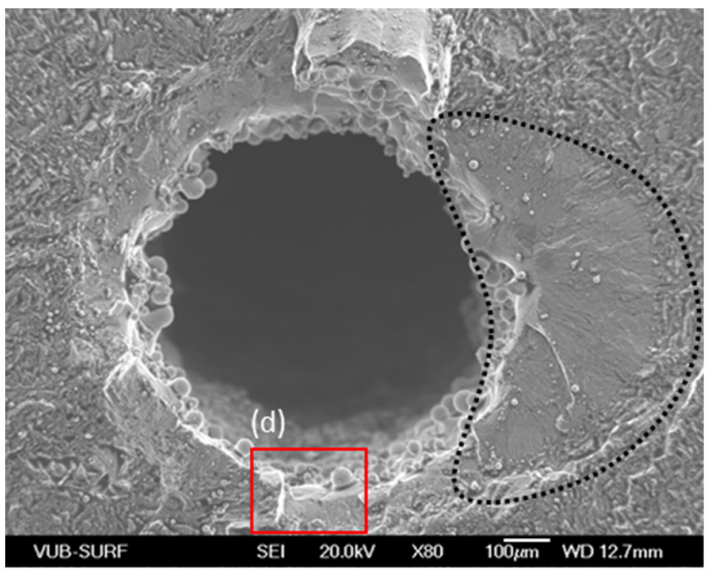

(c)

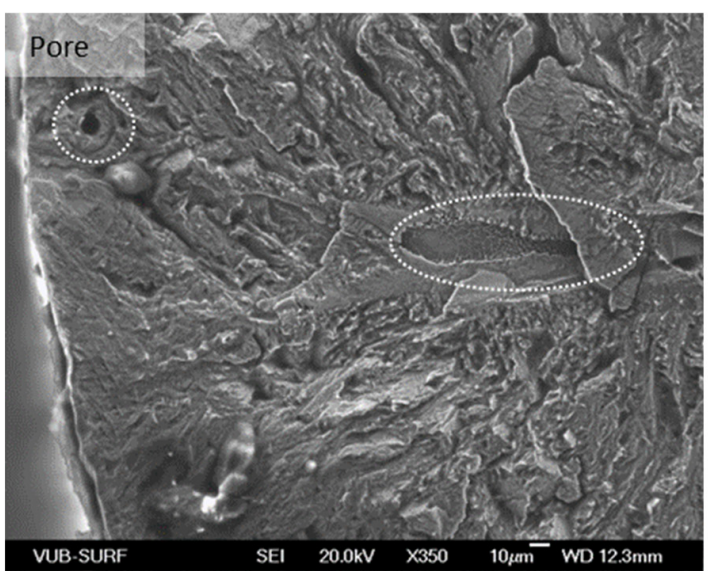

(b)

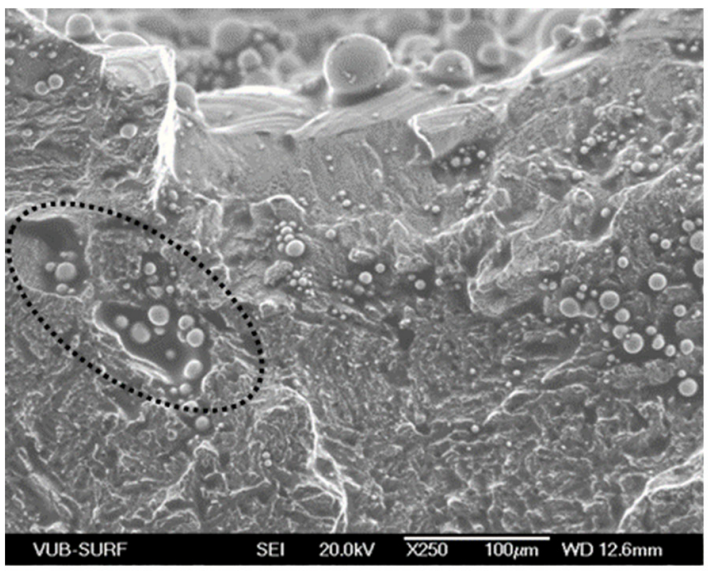

(d)

Figure 6. Fracture surface of Specimen 5 with maximum stress of $537 \mathrm{MPa}$. The fracture surface is shown in (a) and the defect is visible in (b); the capillary region is depicted in (c) in high magnification, while (d) shows un-molten powder particles concentrated around the capillary.

Similar observations on the defects' nature are also noticed in Figure 7, where the fracture surface of Specimen 3 is depicted. Specimen 3 is the only specimen for which the eSHM system detected the crack in the stress level of $323 \mathrm{MPa}$, which is considered a low value compared to the other specimens. As shown in Figure 7a, the fracture surface shows crack initiation from sub-surface defects really close to the surface of the specimen. Figure 7b,c show SEM images from some of the concentrated defects. It is obvious that un-molten regions with concentrated pore inclusions can act as detrimental stress concentrators. In general, the total surface of the current sample included a certain amount of pores and gas inclusions that were encapsulated during the SLM process (see ellipse in Figure 7d). The high amount of defects in this sample explains the fast failure during fatigue at low stress level. However, from the fractographic pictures, it is revealed that Specimen 5 (Figure 6) had more internal defects than Specimen 3 (Figure 7). As a result, the crack path of Specimen 5 had more internal defects than the one of Specimen 3. Those observations could also be connected with the difference of pressure behaviors of these specimens from Section 3.2. 


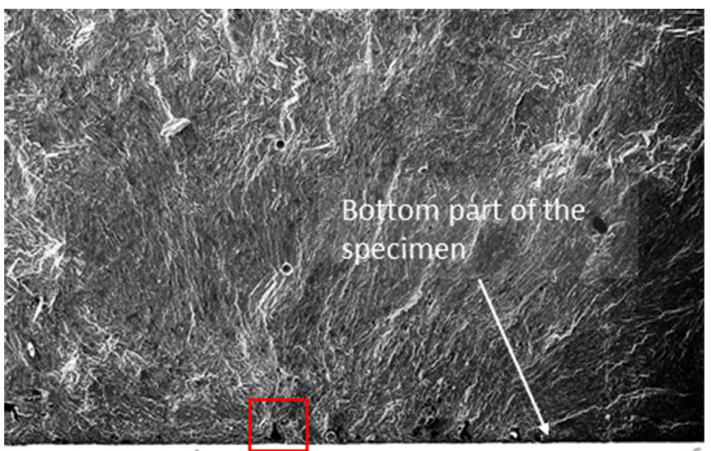

(b)

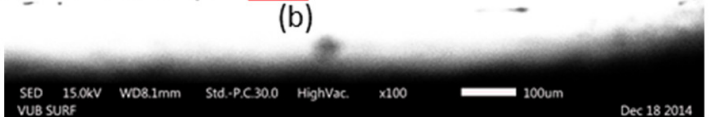

(a)

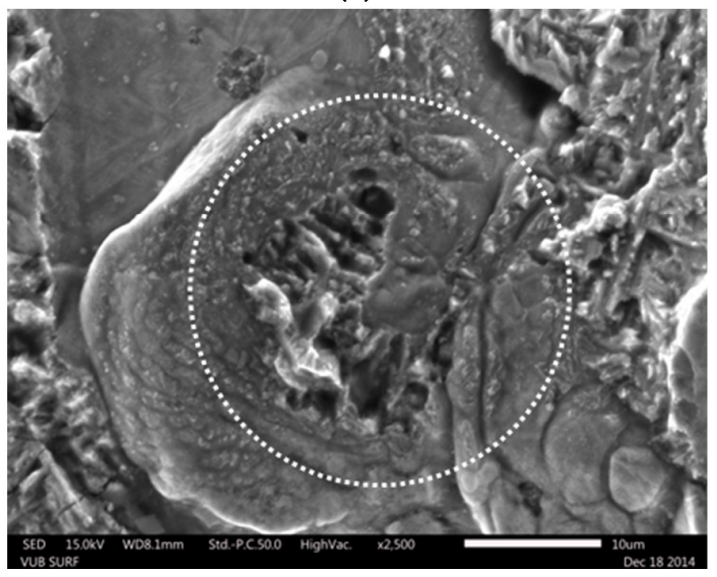

(c)

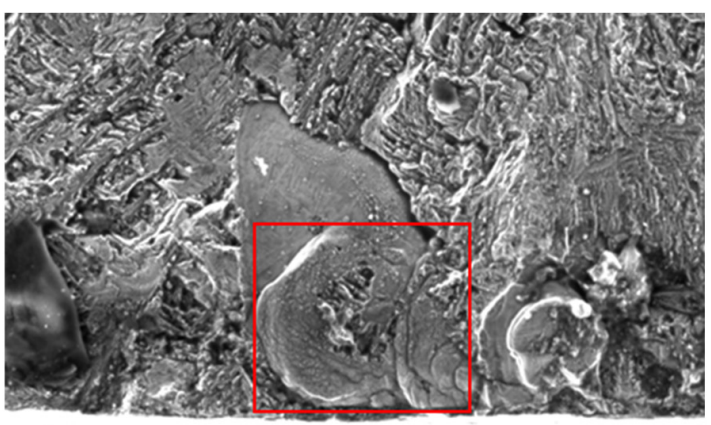

(c)

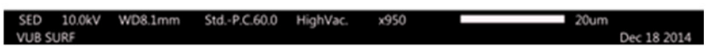

(b)

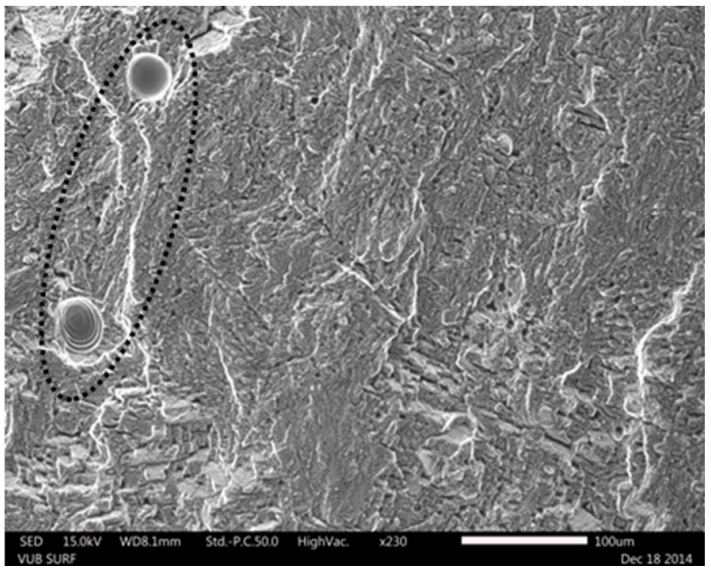

(d)

Figure 7. Fracture surface of Specimen 3 with maximum stress of $323 \mathrm{MPa}$. The defect is shown in (a), a close-up of the defect in $(\mathbf{b}, \mathbf{c})$ while a part of the fracture surface with gas inclusions is depicted in (d).

The former fracture patterns with the defects were also observed for the specimens that are not shown in this article. These defects have a negative impact on the fatigue life and resulted in low stress level failure. Processes like hot isostatic pressing could also decrease the porosity, but, still, micropores (bellow $22 \mu \mathrm{m}$ ) located close to the surface could drastically affect the fatigue life, as is demonstrated in the literature [28]. In all cases, the capillary itself did not negatively affect the crack nucleation and thus did not act as a stress concentrator for the current test specifications.

Apart from the internal defects and the residual stresses, other parameters that can have an impact on the crack initiation are crystallographic anisotropy or surface finish, while in some cases complex microstructures may cause crack initiation during fatigue [31]. It is known that Ti6Al4V contains both $\alpha$ and $\beta$ phases. The fatigue life of Ti6Al4V components is also affected by the morphology of both phases. The crack nucleation in lamellar $\alpha+\beta$ microstructures is known to initiate at slips bands within $\alpha$ (or $\alpha^{\prime}$ ) lamellae or at $\alpha$ (or $\alpha^{\prime}$ ) along prior $\beta$ grain boundaries [10,32]. In Figure 8, the micrographs of the macrostructure of the SLM Specimen 3 and the conventional Specimen 3 are compared. In the side view of the SLM specimen (Figure 8a), large, vertical columnar prior $\beta$ phase grains are present. The long columnar $\beta$ phase grains are growing along the BD. This is a result of the re-melting of the prior solidified layers during the SLM process, which leads to an epitaxial and directional solidification [5]. The macrostructure of the top view of the SLM specimen is shown in Figure $8 \mathrm{~b}$. Acicular $\alpha^{\prime}$ martensitic formed inside the $\beta$ phase grains. On the other hand, there is a distinct difference between the SLM macrostructures and the macrostructure of the conventional Ti6Al4V specimens, shown in Figure 8c. The macrostructure of the conventional Ti6Al4V consists of a bimodal distribution of primary $\alpha$ phase grains (light color) and lamellar $\alpha+\beta$ colonies within small 
transformed $\beta$ grains. Figure 8c shows that the conventional Ti6Al4V almost completely consists of primary alpha grains, with only a few transformed beta grains in which a coarse lamellar $\alpha+\beta$ is found. It is demonstrated in the literature that lamellar microstructures have a beneficial effect on the crack growth rates of small cracks. This is attributed to the high density grain boundaries. On the other hand, bimodal microstructures have a good resistance against crack initiation due to the finer grains that are reducing the dislocation slip lengths [33].

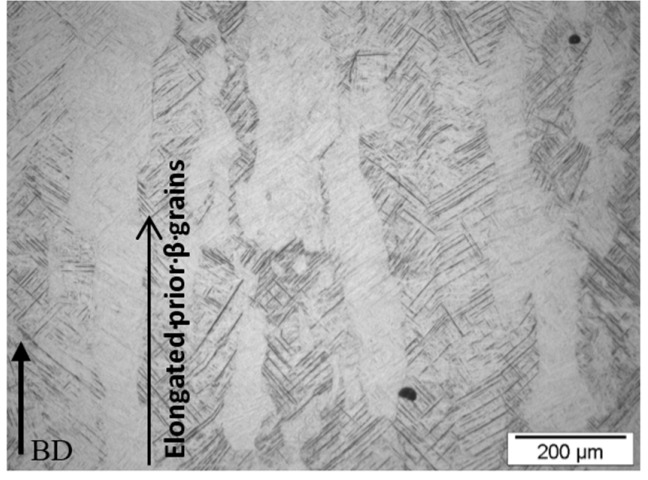

(a)

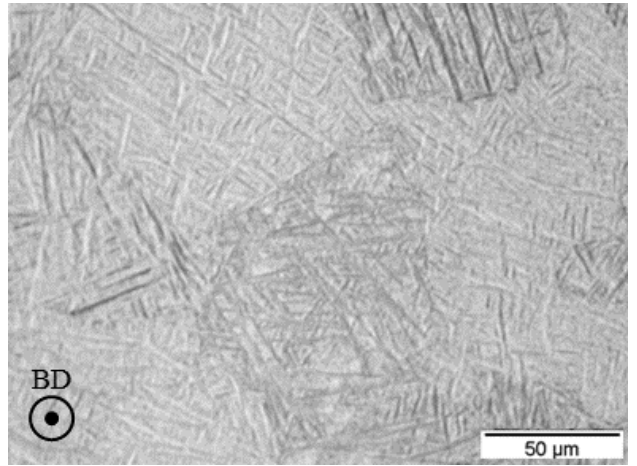

(b)

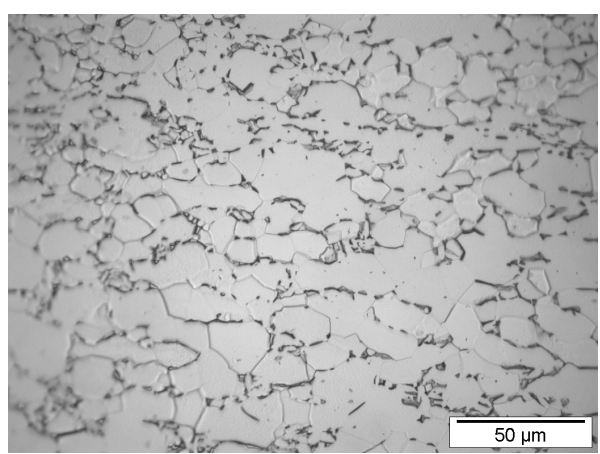

(c)

Figure 8. Micrographs of the macrostructure of (a) side view parallel to the building direction (BD) of Ti6Al4V SLM Specimen 3; (b) top view perpendicular to the BD of Ti6Al4V SLM Specimen 3 and (c) top view of the Ti6Al4V conventional specimen.

\subsection{Stress Analysis Based on Finite Element Simulations}

The stress levels reached during testing at the bottom edge of the capillary and at the bottom of the specimens were calculated by FEM simulations. The comparison of the calculated stresses provides further understanding of the crack initiation positions observed in the SEM images. Four-point bending specimens as shown in Figure 9 were considered. For both capillary structures (period of $20 \mathrm{~mm}$ and $22.4 \mathrm{~mm}$ ) this comparison was performed at a loading of $20 \mathrm{kN}$, which was the crack initiation loading for Specimen 3. Two paths, illustrated in Figure 9, were considered for extracting the maximum principle stresses: at the bottom (edge) of the capillary and at the bottom of the specimen.

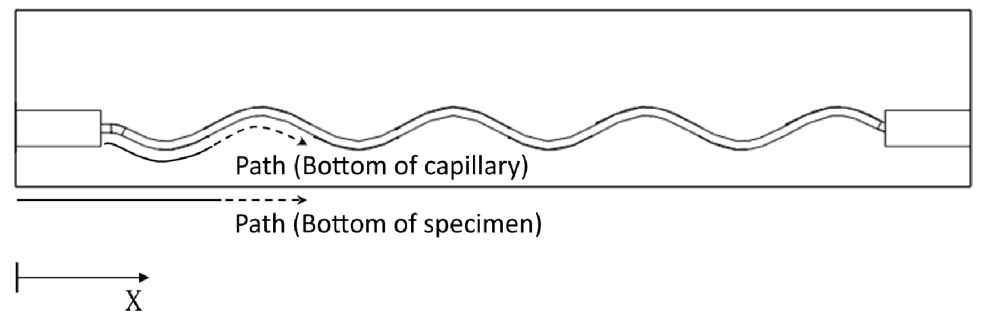

Figure 9. Schematic description of the paths used for extracting stresses in the numerical simulations. 
The results for the additive manufactured specimens are depicted in Figure 10, while the crack locations of the specimens are indicated with arrows. In order to compare the stresses at the bottom of both the specimen and the capillary, the length interval of $70 \mathrm{~mm}$ at the middle of the specimen is considered. According to four-point bending setup (see Figure 2), the center region of $50 \mathrm{~mm}$ is subjected to the highest stress level in the longitudinal direction. The results shown in Figure 10a are representative for Specimens 1, 2, 3, 4 and the SR specimen with a period of the sinusoidal shape of $20 \mathrm{~mm}$. The failure of Specimens 2 and 3 occurred at $X=75 \mathrm{~mm}$ and $80 \mathrm{~mm}$ respectively, while in the SR specimen the failure occurred at the position of $79 \mathrm{~mm}$. The crack initiation sites were located on the bottom of the specimen. At these positions, the stress level at the bottom of the specimen is high, while stresses are rather low at the bottom of the capillary, see Figure 10a. Specimens 1 and 4 broke respectively at $X=84 \mathrm{~mm}$ and $45 \mathrm{~mm}$. From (not-shown) SEM images it was observed that the crack was initiated from the capillary region in these specimens. Considering that the calculated stress level at the capillary's sites is high at $X=84 \mathrm{~mm}$ and $45 \mathrm{~mm}$ (Figure 10a), it can be concluded that these initiation locations were a result of the combination of high stress levels and internal defects like porosity close to the capillary. The failure of Specimens 5 and 6, with a period of the sinusoidal shape of $22.4 \mathrm{~mm}$, occurred respectively at $X=71 \mathrm{~mm}$ and $X=73 \mathrm{~mm}$. In the case of Specimen 6 , the crack initiated from an internal defect close to the bottom of the specimen, while in Specimen 5 the main crack initiated from the bottom of the specimen (see SEM images shown Figures 5 and 6). According to the stress analysis results of Figure 10b, the stress level around the capillary is quite low at $X=71 \mathrm{~mm}$ and $73 \mathrm{~mm}$, while the stress level at the bottom of the specimen is substantial, and this leads to the crack initiation.

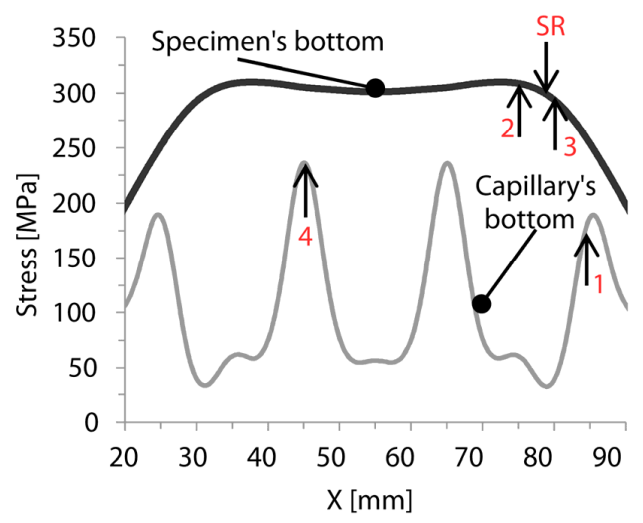

(a)

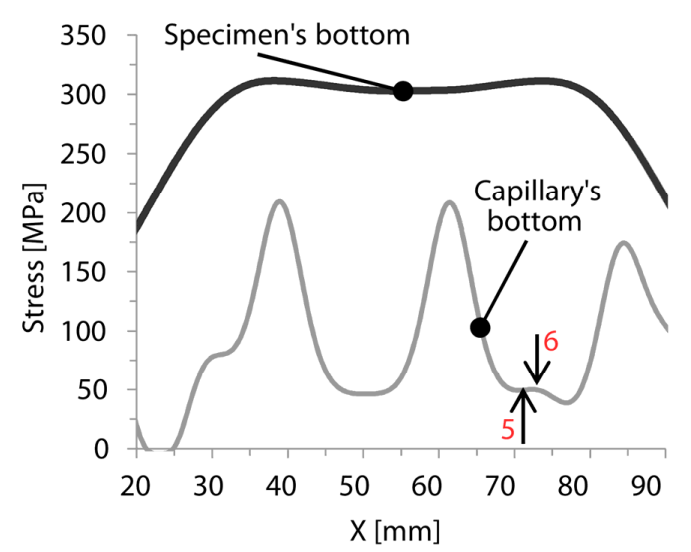

(b)

Figure 10. Comparing the stress distributions for a load of $20 \mathrm{kN}$ for the capillary structure with (a) a period of $20 \mathrm{~mm}$ (Specimens 1, 2, 3, 4 and stress relieved (SR)); and (b) a period of $22.4 \mathrm{~mm}$ (Specimens 5 and 6).

For both types of capillary geometries, the calculated stress levels at the bottom of the capillaries are lower than the stresses at the specimen's bottom. From this perspective, it is expected that cracks would always initiate from the bottom of the specimens. This highlights the fact that an integrated capillary would not have a critical impact on the crack initiation in an SLM component. It should be mentioned that the capillary surface is expected to have roughness in the order of the powder particle [34]. Internal defects on the capillary region and the surface roughness of the capillary could increase the local stress level and as a consequence affect the crack initiation behavior. This phenomena are extensively discussed by Lipinski et al. [34]. However, in the current study the simulations do not take into account parameters such as defects or surface roughness. From the fracture surface analysis performed with the SEM, it was observed that in some cases cracks initiated from the region of the capillary. This is principally due to the defects present in the specimens, rather than the presence of the capillary itself. The location of these defects (porosities and lack-of-fusion regions) can be closer or 
further away from the capillary or the sample border. These locations are essentially unpredictable, and, as a result, it is also difficult to predict the location of the crack initiation during the fatigue tests. This explains the random scatter on the crack initiation locations identified for the different specimens with the SEM analysis.

\section{Conclusions}

In this study, the functionality of a novel structural health monitoring system on Ti6Al4V components produced by selective laser melting was presented. The specimens that were used for this study were subjected to high cycle fatigue in as-built conditions. All the additive manufactured components had an integrated structural health monitoring system which successfully detected the crack before the final failure. In order to confirm that the integrated system had no influence on the crack initiation behavior during fatigue and to define the cause of the crack, fracture surface analysis was also performed. It was shown that, for the SLM specimens, crack nucleation sites were developed due to near-surface defects such as concentrated pores or lack-of-fusion regions. These defects have a negative impact on the fatigue life and can act as stress concentrators. Additionally, tests on conventional material without a capillary showed almost no scatter, while results for the SLM specimens varied significantly. Furthermore, finite element stress analysis showed that the stress around the capillary is lower than those experienced at the outer surfaces of the specimen. These results clearly indicate the importance of the imperfections on the fatigue life of an SLM component and the applicability of structural health monitoring systems. Processes like hot isostatic pressing will decrease the porosity, but without closing the near-surface defects that are open to the surface. Other parameters like microstructure, surface roughness and residual stresses that are not extensively investigated in the current paper are also of high importance. The residual stresses and microstructure could significantly affect the crack nucleation and the crack propagation during fatigue, while the surface finishing of the capillaries could be crucial for crack nucleation. Nevertheless, it can be concluded that SLM components in a combination with a structural health monitoring system could be beneficial for industrial applications. Further investigations should be conducted on the eSHM system in order to enable extra functionality on the crack localization and to improve the fatigue response of the additive manufacturing components with the integrated system. Important parameters that will be extensively investigated in the future are the residual stresses that are developed during the AM process in metallic components with the integrated eSHM system and the roughness parameter of the capillaries.

Acknowledgments: Research funded by an SBO Project grant 110070: eSHM with AM of the Agency for Innovation by Science and Technology (IWT).

Author Contributions: All authors contributed to the work presented in this paper, and to the writing of the final manuscript. Maria Strantza and Dieter de Baere conceived and designed the experiments; Maria Strantza performed the experiments; Reza Vafadari and Wim van Paepegem performed the finite element simulations; Bey Vrancken performed the stress relief and contributed to the analysis of the data; Isabelle Vandendael and Herman Terryn contributed on the fracture analysis; Danny van Hemelrijck, Dieter de Baere and Patrick Guillaume contributed to the development of the eSHM system and discussion of the results.

Conflicts of Interest: The authors declare no conflict of interest.

\section{Abbreviations}

The following abbreviations are used in this manuscript:

$\begin{array}{ll}\text { AM } & \text { Additive manufacturing } \\ \text { SLM } & \text { Selective laser melting } \\ \text { SHM } & \text { Structural health monitoring } \\ \text { eSHM } & \text { effective structural health monitoring } \\ \text { FEM } & \text { Finite element method } \\ \text { AB } & \text { As-built } \\ \text { SR } & \text { Stress relieved; stress relief }\end{array}$




\section{References}

1. Gibson, I.; Rosen, D.W.; Stucker, B. Additive Manufacturing Technologies; Springer: Berlin/Heidelberg, Germany, 2010.

2. Levy, G.N.; Schindel, R.; Kruth, J.P. Rapid manufacturing and rapid tooling with Layer Manufacturing (LM) technologies, state of the art and future perspectives. CIRP Ann. Manuf. Technol. 2003, 52, 589-609. [CrossRef]

3. Kruth, J.P.; Froyen, L.; van Vaerenbergh, J.; Mercelis, P.; Rombouts, M.; Lauwers, B. Selective laser melting of iron-based powder. J. Mater. Process. Technol. 2004, 149, 616-622. [CrossRef]

4. Kruth, J.-P.; Mercelis, P.; van Vaerenbergh, J.; Froyen, L. Binding mechanisms in selective laser sintering and selective laser melting. Rapid Prototyp. 2005, 11, 26-36. [CrossRef]

5. Thijs, L.; Verhaeghe, F.; Craeghs, T.; van Humbeeck, J.; Kruth, J.-P. A study of the microstructural evolution during selective laser melting of Ti-6Al-4V. Acta Mater. 2010, 58, 3303-3312. [CrossRef]

6. Vilaro, T.; Colin, C.; Bartout, J.D. As-fabricated and heat-treated microstructures of the Ti-6Al-4V alloy processed by selective laser melting. Metall. Mater. Trans. A Phys. Metall. Mater. Sci. 2011, 42, 3190-3199. [CrossRef]

7. Vrancken, B.; Cain, V.; Knutsen, R.; van Humbeeck, J. Residual stress via the contour method in compact tension specimens produced via selective laser melting. Scr. Mater. 2014, 87, 29-32. [CrossRef]

8. Gorny, B.; Niendorf, T.; Lackmann, J.; Thoene, M.; Troester, T.; Maier, H.J. In situ characterization of the deformation and failure behavior of non-stochastic porous structures processed by selective laser melting. Mater. Sci. Eng. A 2011, 528, 7962-7967. [CrossRef]

9. Brandl, E.; Heckenberger, U.; Holzinger, V.; Buchbinder, D. Additive manufactured AlSi10Mg samples using Selective Laser Melting (SLM): Microstructure, high cycle fatigue, and fracture behavior. Mater. Des. 2012, 34, 159-169. [CrossRef]

10. Gong, H.; Rafi, K.; Starr, T.; Stucker, B.E. Effect of defects on fatigue tests of as-built Ti-6Al-4V parts fabricated by selective laser melting. In Proceedings of the Solid Freeform Fabrication Symposium, Austin, TX, USA, 6-8 August 2012; pp. 499-506.

11. Wang, Q.G.; Apelian, D.; Lados, D.A. Fatigue behavior of A356-T6 aluminum cast alloys. Part I. Effect of casting defects. J. Light Met. 2001, 1, 73-84. [CrossRef]

12. Janssen, M.; Zuidema, J.; Wanhill, R. Fracture Mechanics, 2nd ed.; Spon Press: Abingdon, UK, 2002.

13. Schijve, J. The significance of fatigue crack initiation for predictions of the fatigue limit of specimens and structures. Int. J. Fatigue 2014, 61, 39-45. [CrossRef]

14. Wulpi, D. Understanding How Components Fail, 2nd ed.; ASTM International: West Conshohocken, PA, USA, 1985.

15. Metals Handbook. Fractography, 9th ed.; ASM: Metals Park, OH, USA, 1990; Volume 12.

16. Farrar, C.R.; Worden, K. An introduction to structural health monitoring. Philos. Trans. A. Math. Phys. Eng. Sci. 2007, 365, 303-315. [CrossRef] [PubMed]

17. Pekedis, M.; Mascerañas, D.; Turan, G.; Ercan, E.; Farrar, C.R.; Yildiz, H. Structural health monitoring for bolt loosening via a non-invasive vibro-haptics human-machine cooperative interface. Smart Mater. Struct. 2015, 24, 085018. [CrossRef]

18. Salowitz, N.; Guo, Z.; Roy, S.; Nardari, R.; Li, Y.; Kim, S.; Kopsaftopoulos, F.; Chang, F. A vision on stretchable bio-inspired networks for intelligent structures. In Proceedings of the International Workshop on Structural Health Monitoring, Dohrmann Grove, CA, USA, 10-12 September 2013.

19. Sharp, N.; Kuntz, A.; Brubaker, C.; Amos, S.; Gao, W.; Gupta, G.; Mohite, A.; Farrar, C.; Mascareñas, D. A bio-inspired asynchronous skin system for crack detection applications. Smart Mater. Struct. 2014, 23, 055020. [CrossRef]

20. Strantza, M.; de Baere, D.; Rombouts, M.; Maes, G.; Guillaume, P.; van Hemelrijck, D. Feasibility study on integrated structural health monitoring system produced by three-dimensional printing. Struct. Heal. Monit. J. 2015, 14. [CrossRef] 
21. Cain, V.; Thijs, L.; van Humbeeck, J.; van Hooreweder, B.; Knutsen, R. Crack propagation and fracture toughness of Ti6Al4V alloy produced by selective laser melting. Addit. Manuf. 2014, 5, 68-76. [CrossRef]

22. Maxwell, D.C.; Nicholas, T. A rapid method for generation of a Haigh diagram for high cycle fatigue. Fatigue Fract. Mech. 1999, 29. [CrossRef]

23. Bellows, R.S.; Muju, S.; Nicholas, T. Validation of the step test method for generating Haigh diagrams for Ti-6Al-4V. Int. J. Fatigue 1999, 21, 687-697. [CrossRef]

24. Wycisk, E.; Solbach, A.; Siddique, S.; Herzog, D.; Walther, F.; Emmelmann, C. Effects of defects in laser additive manufactured Ti-6Al-4V on fatigue properties. Phys. Procedia 2014, 56, 371-378. [CrossRef]

25. Mower, T.M.; Long, M.J. Mechanical behavior of additive manufactured, powder-bed laser-fused materials. Mater. Sci. Eng. A 2016, 651, 198-213. [CrossRef]

26. Yavari, S.A.; Wauthlé, R.; van der Stok, J.; Riemslag, A.C.; Janssen, M.; Mulier, M.; Kruth, J.P.; Schrooten, J.; Weinans, H.; Zadpoor, A.A. Fatigue behavior of porous biomaterials manufactured using selective laser melting. Mater. Sci. Eng. C 2013, 33, 4849-4858. [CrossRef] [PubMed]

27. Hibbitt, K. ABAQUS: User's Manual; Hibbitt, Karlsson, and Sorensen, Inc.: Pawtucket, RI, USA, 2013.

28. Leuders, S.; Thöne, M.; Riemer, A.; Niendorf, T.; Tröster, T.; Richard, H.A.; Maier, H.J. On the mechanical behavior of titanium alloy TiAl6V4 manufactured by selective laser melting: Fatigue resistance and crack growth performance. Int. J. Fatigue 2013, 48, 300-307. [CrossRef]

29. Rangaswamy, P.; Griffith, M.L.; Prime, M.B.; Holden, T.M.; Rogge, R.B.; Edwards, J.M.; Sebring, R.J. Residual stresses in LENS components using neutron diffraction and contour method. Mater. Sci. Eng. A 2005, 399, 72-83. [CrossRef]

30. Wu, A.S.; Brown, D.W.; Kumar, M.; Gallegos, G.F.; King, W.E. An experimental investigation into additive manufacturing-induced residual stresses in 316L stainless steel. Metall. Mater. Trans. A 2014, 45, 6260-6270. [CrossRef]

31. Chan, K.S. Roles of microstructure in fatigue crack initiation. Int. J. Fatigue 2010, 32, 1428-1447. [CrossRef]

32. Song, Z.M.; Lei, L.M.; Zhang, B.; Huang, X.; Zhang, G.P. Microstructure dependent fatigue cracking resistance of Ti-6.5Al-3.5Mo-1.5Zr-0.3Si alloy. J. Mater. Sci. Technol. 2012, 28, 614-621. [CrossRef]

33. Nalla, R.K.; Boyce, B.L.; Campbell, J.P.; Peters, J.O.; Ritchie, R.O. Influence of microstructure on high-cycle fatigue of Ti-6Al-4V: Bimodal vs. lamellar structures. Metall. Mater. Trans. A 2002, 33, 899-918. [CrossRef]

34. Lipinski, P.; Barbas, A.; Bonnet, A.S. Fatigue behavior of thin-walled grade 2 titanium samples processed by selective laser melting. Application to life prediction of porous titanium implants. J. Mech. Behav. Biomed. Mater. 2013, 28, 274-290. [CrossRef] [PubMed]

(C) 2016 by the authors; licensee MDPI, Basel, Switzerland. This article is an open access article distributed under the terms and conditions of the Creative Commons by Attribution (CC-BY) license (http://creativecommons.org/licenses/by/4.0/). 